\section{Pacific Northwest}

National Laboratory

Operated by Battelle for the

U.S. Department of Energy

\title{
Raman Spectroscopic Studies of Chemical Speciation in Calcium Chloride Melts
}

CF Windisch Jr.

CA Lavender

February 2005

Prepared for the U.S. Department of Energy under Contract DE-AC05-76RL01830 


\title{
DISCLAIMER
}

This report was prepared as an account of work sponsored by an agency of the United States Government. Neither the United States Government nor any agency thereof, nor Battelle Memorial Institute, nor any of their employees, makes any warranty, express or implied, or assumes any legal liability or responsibility for the accuracy, completeness, or usefulness of any information, apparatus, product, or process disclosed, or represents that its use would not infringe privately owned rights. Reference herein to any specific commercial product, process, or service by trade name, trademark, manufacturer, or otherwise does not necessarily constitute or imply its endorsement, recommendation, or favoring by the United States Government or any agency thereof, or Battelle Memorial Institute. The views and opinions of authors expressed herein do not necessarily state or reflect those of the United States Government or any agency thereof.

\author{
PACIFIC NORTHWEST NATIONAL LABORATORY \\ operated by \\ BATTELLE \\ for the \\ UNITED STATES DEPARTMENT OF ENERGY \\ under Contract DE-AC05-76RL01830
}

Printed in the United States of America
Available to DOE and DOE contractors from the Office of Scientific and Technical Information,
P.O. Box 62, Oak Ridge, TN 37831-0062;
ph: (865) 576-8401
fax: $(865) 576-5728$
email: reports@adonis.osti.gov

\footnotetext{
Available to the public from the National Technical Information Service, U.S. Department of Commerce, 5285 Port Royal Rd., Springfield, VA 22161 ph: (800) 553-6847 fax: $(703) 605-6900$ email: orders@ntis.fedworld.gov online ordering: http://www.ntis.gov/ordering.htm
}

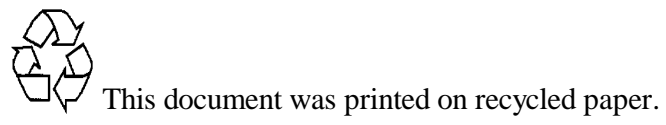


PNNL-15061

\section{Raman Spectroscopic Studies of Chemical Speciation in Calcium Chloride Melts}

C. F. Windisch Jr. and C. A. Lavender

February 2005

Prepared for the Defense Advanced Research

Projects Agency (DARPA) and the U.S. Department

of Energy under Contract DE-AC06-76RLO1830

Pacific Northwest National Laboratory

Richland, WA 99352 


\section{Executive Summary}

Raman spectroscopy was applied to $\mathrm{CaCl}_{2}$ melts at $900^{\circ} \mathrm{C}$ under both non-electrolyzed and electrolyzed conditions. The later used titania cathodes supplied by TIMET, Inc. and graphite anodes. Use of pulse-gating to collect the Raman spectra successfully eliminated any interference from black-body radiation and other stray light. The spectrum of molten $\mathrm{CaCl}_{2}$ exhibited no distinct, resolvable bands that could be correlated with a calcium chloride complex similar to $\mathrm{MgCl}_{4}{ }^{2-}$ in $\mathrm{MgCl}_{2}$ melts. Rather, the low frequency region of the spectrum was dominated by a broad "tail" arising from collective oscillations of both charge and mass in the molten salt "network." Additions of both $\mathrm{CaO}$ and $\mathrm{Ca}$ at concentrations of a percent or two resulted in no new features in the spectra. Addition of $\mathrm{CO}_{2}$, both chemically and via electrolysis at concentrations dictated by stability and solubility at $900^{\circ} \mathrm{C}$ and 1 bar pressure, also produced no new bands that could be correlated with either dissolved $\mathrm{CO}_{2}$ or the carbonate ion. These results indicated that Raman spectroscopy, at least under the conditions evaluated in the research, was not well suited for following the reactions and coordination chemistry of calcium ions, nor species such as dissolved metallic $\mathrm{Ca}$ and $\mathrm{CO}_{2}$ that are suspected to impact current efficiency in titanium electrolysis cells using molten $\mathrm{CaCl}_{2}$. Raman spectra of TIMET titania electrodes were successfully obtained as a function of temperature up to $900^{\circ} \mathrm{C}$, both in air and in-situ in $\mathrm{CaCl}_{2}$ melts. However, spectra of these electrodes could only be obtained when the material was in the unreduced state. When reduced, either with hydrogen or within an electrolysis cell, the resulting electrodes exhibited no measurable Raman bands under the conditions used in this work.

Since an understanding of the molecular structural factors and compositional issues that affect current efficiency is paramount to successful operation of the titanium reduction cells, it is recommended that the search for methods sensitive to them continue. Among possible alternative approaches are the use of elemental mapping using electron spectroscopic techniques on carefully quenched cells and more advanced electroanalytical methods, both ac and dc, that can be applied in-situ during electrolysis. 


\section{Acknowledgments}

This work was supported by the Defense Advanced Research Projects Agency (DARPA) under MIPR \#04-T322-00. The Pacific Northwest National Laboratory (PNNL) is operated by Battelle Memorial Institute for the U.S. Department of Energy under Contract DE-AC06-76RLO 1830. The authors would also like to thank Nat Saenz and Nathan Canfield, both PNNL staff members, for their assistance in obtaining the microscopy and XRD data, respectively. 


\section{Contents}

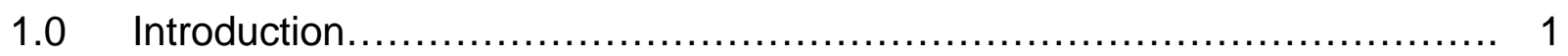

1.1 Key Current Efficiency Issues................................... 1

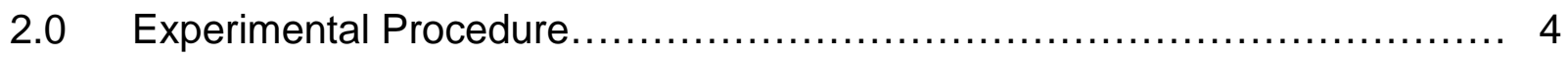

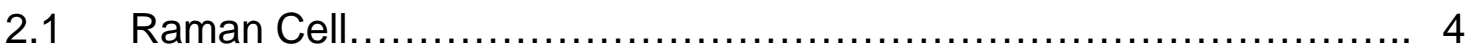

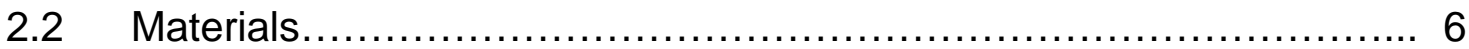

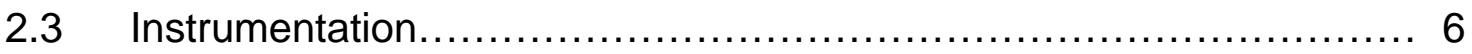

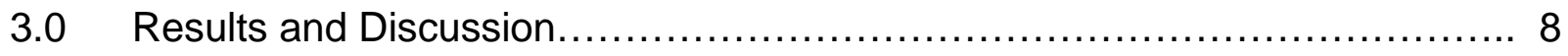

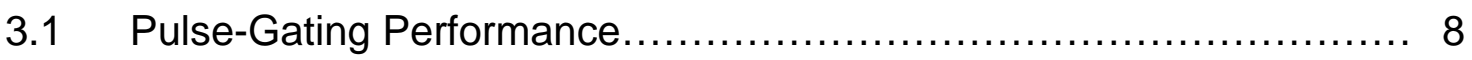

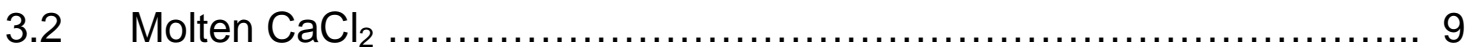

3.3 Effects of $\mathrm{CaO}$ and $\mathrm{Ca}$ Addition................................. 13

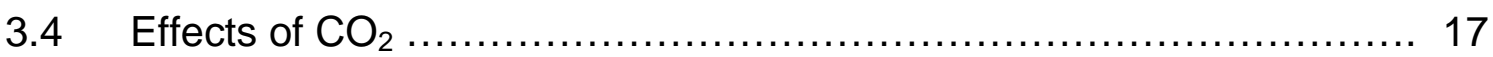

3.5 TIMET Cathode Material.......................................... 19

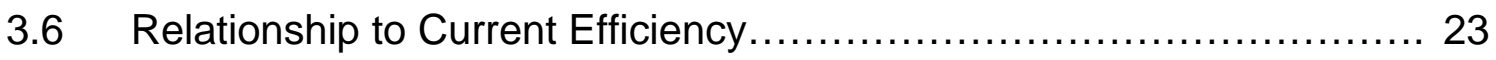

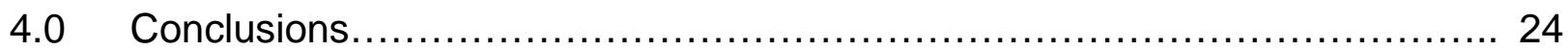

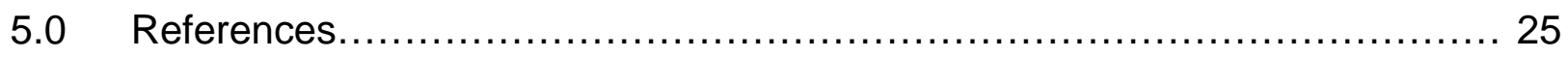




\subsection{Introduction}

The widespread implementation of titanium into new markets such as the automotive industry has been limited by the high cost to produce titanium products, a significant part of which arises from the cost of reducing the titanium ore. Currently, the most common industrial process for reducing the ore is a batch chemical reduction of chlorinated titania using Mg. Recently, the Cambridge University published a "breakthrough" technology for the electrolytic reduction of titania using a porous cathode, a carbon anode, and molten $\mathrm{CaCl}_{2}$ electrolyte. A study funded by DOE/EE projected that the cost of Ti metal could be roughly cut in half by using this approach, provided the cathode could be made from rutile ore and that the cell would scale up without loss of efficiency. Recent scale-up efforts by TIMET have been promising. However, as is the case with most electrochemical cells, current efficiency appears to limit the cell production under some conditions. The purpose of this work is to determine if Raman spectroscopy can identify the sources of current inefficiency in TIMET cells and, if so, to help provide recommendations for how to minimize them.

\subsection{Key Current Efficiency Issues}

Recently scaled-up TIMET reduction cells exhibit difficulty in maintaining high current efficiency throughout the "lifetime" of a cathode reducing the overall efficiency. While large amounts of the ore can be reduced in the early stages of the reduction process, cell currents remain high at longer times, even as $\mathrm{CO}_{2}$ production (and, presumably, $\mathrm{Ti}$ production) drops off. These sustained currents are believed to arise from parasitic reactions that occur in parallel with the primary cathodic reaction involving the reduction of titania ore to Ti metal. Among other consequences, they make it difficult to determine when the process is completed and the cathode can be removed, and, even more importantly, how on-line current/voltage information can be used, much like it is in the aluminum reduction industry, to optimize the performance of an operating cell.

Based on recent analysis by TIMET, there are two most likely candidates for the parasitic reactions. The first is proposed to involve dissolved Ca metal that is produced along with Ti metal at the cathode. The postulate is that, if the dissolved $\mathrm{Ca}$ metal content is high enough, the melt will begin to function as an electronic conductor, providing a short-circuit path between the electrodes without accompanying electrochemical reactions. The second possibility involves $\mathrm{CO}_{2}$ produced at the anode. The $\mathrm{CO}_{2}$ gas dissolves, transports to the cathode where it is subsequently reduced to either $\mathrm{C}$ or Ti carbide. Both of these mechanisms will be strongly influenced by the properties of the melt as it evolves during electrolysis. For example, as $\mathrm{TiO}_{2}$ is reduced at the cathode, oxide ions are produced that migrate to the anode where they combine with oxidized $\mathrm{C}$ to produce $\mathrm{CO}_{2}$. However, $\mathrm{CO}_{2}$ solubility will also be influenced by the oxide ion content of the melt. Hence, both the operation of the cell and the fate of $\mathrm{CO}_{2}$ will depend on the transport and balance of alkalinity between one electrode and the 
other. This mechanism, how it is influence by electrolyte conditions, and others reactions involving the two proposed problematic species, $\mathrm{CO}_{2}$ and $\mathrm{Ca}$, are not easily determined in electro-reduction cells without the use of supporting analytical techniques. In particular, techniques are needed that (1) are sensitive to and can discriminate between different chemical species in the melt, and (2) can be applied in-situ, i.e. in the melt at temperature and/or during electrolysis.

Raman spectroscopy is an inelastic light scattering technique that was previously used with success in studies on several molten salt systems [1-7] including $\mathrm{MgCl}_{2}$ [7]. In the case of molten $\mathrm{MgCl}_{2}$, a clearly resolved band was observed at $205 \mathrm{~cm}^{-1}$ that was assigned to the symmetric stretch of the tetrahedral $\mathrm{MgCl}_{4}{ }^{2-}$ species. Other studies showed that this band shifted by as much as $44 \mathrm{~cm}^{-1}$ (to $249 \mathrm{~cm}^{-1}$ ) and also appeared to change shape as a function of melt composition [7]. This indicates that the structure and/or environment of the $\mathrm{MgCl}_{4}{ }^{2-}$ complex were perturbed by melt composition and that this perturbation could be observed, through frequency shifts and perhaps band broadening.

Since Raman spectroscopy was found to be useful in studying similar molten salt systems, it was considered worthwhile to determine if the technique could be applied to molten $\mathrm{CaCl}_{2}$-based salts under conditions that were similar to those used in TIMET reduction cells. Successful identification of chemical species and their behavior might increase knowledge of melt chemistry sufficiently to explain losses of current efficiency in these cells and lead to corrective actions. Toward this end, the research described in this report focused on evaluating Raman spectroscopy as a tool for studying $\mathrm{CaCl}_{2}$ melt chemistry under a set of conditions that, at least partly, reproduced those in TIMET reduction cells.

As part of the effort to diagnose $\mathrm{CaCl}_{2}$ melt chemistry, the proposed work involved designing and using a Raman spectroscopic setup that minimized black-body background radiation to a greater extent than procedures previously utilized in the literature on molten $\mathrm{MgCl}_{2}$ or other similar molten salts. Most of the previous studies in the literature were performed at lower temperatures (significantly lower in most cases) than used in TIMET reduction cells. The TIMET reduction cells operate at $900^{\circ} \mathrm{C}$. At this temperature, black-body emission intensity is so great that any Raman bands, especially at low frequencies where metal-chloride vibrations are expected, will be completely obscured unless special measures are taken. Consequently, in conjunction with studying $\mathrm{CaCl}_{2}$ melt chemistry, this research also evaluated a technique for minimizing the black-body interference from these melts. This technique, called "pulsegating," was adapted from similar procedures sometimes used in our laboratory and others to filter out interference from external radiation sources.

The specific objectives of the proposed work were to: (1) determine if pulse-gating can be used to minimize interference from black-body radiation from molten $\mathrm{CaCl}_{2}$-based melts at $900^{\circ} \mathrm{C}$, (2) obtain Raman spectrum of molten $\mathrm{CaCl}_{2}$ at $900^{\circ} \mathrm{C}$ and determine 
whether there are any spectra features that can be related to complexes in the melt, (3) determine whether any new spectra features appear as a result of adding $\mathrm{CaO}$ or $\mathrm{Ca}$ metal to the melt or whether and how bands due to $\mathrm{CaCl}_{2}$ are perturbed by these additions, (4) determine whether the presence of $\mathrm{CO}_{2}$ can be detected in the melt, (5) obtain Raman spectra of TIMET $\mathrm{TiO}_{2}$ electrodes as a function of temperature and during electrochemical polarization in molten $\mathrm{CaCl}_{2}$, and (6) relate the above results to current efficiency issues, if possible. 


\subsection{Experimental Procedure}

\subsection{Raman Cell}

The Raman cell and accompanying furnace that was designed and fabricated for this study is shown in Figs. 1 and 2. The cell was made from quartz and was approximately six inches tall with a 1-inch-diameter bottom quartz window. The furnace walls were also quartz. The titania "cathode" was a small sample of TIMET titania cathode material, approximately $1 \mathrm{~cm}$ in diameter that was cemented to the bottom of an alumina tube with Aremco Products (Valley Cottage, NY) Ceramabond hightemperature cement. The sample was angled at 45 degrees relative to the incident laser beam. The carbon "anode" was a 3" long, 1-cm diameter POCO graphite rod that was also angled at the bottom at $45^{\circ}$. The furnace was made from wound Pt wire and heating was performed with a Variac using the thermocouple readout to gauge the voltage setting. Normally, it took about $1 / 2$ hour of gradual heating to reach $900^{\circ} \mathrm{C}$. Experiments were run for as long as $4-5$ hours. For highly alkaline media (after adding $\mathrm{CaO}$ ), it appeared the quartz windows and sides of the cell clouded quicker, possibly due to chemical reaction.

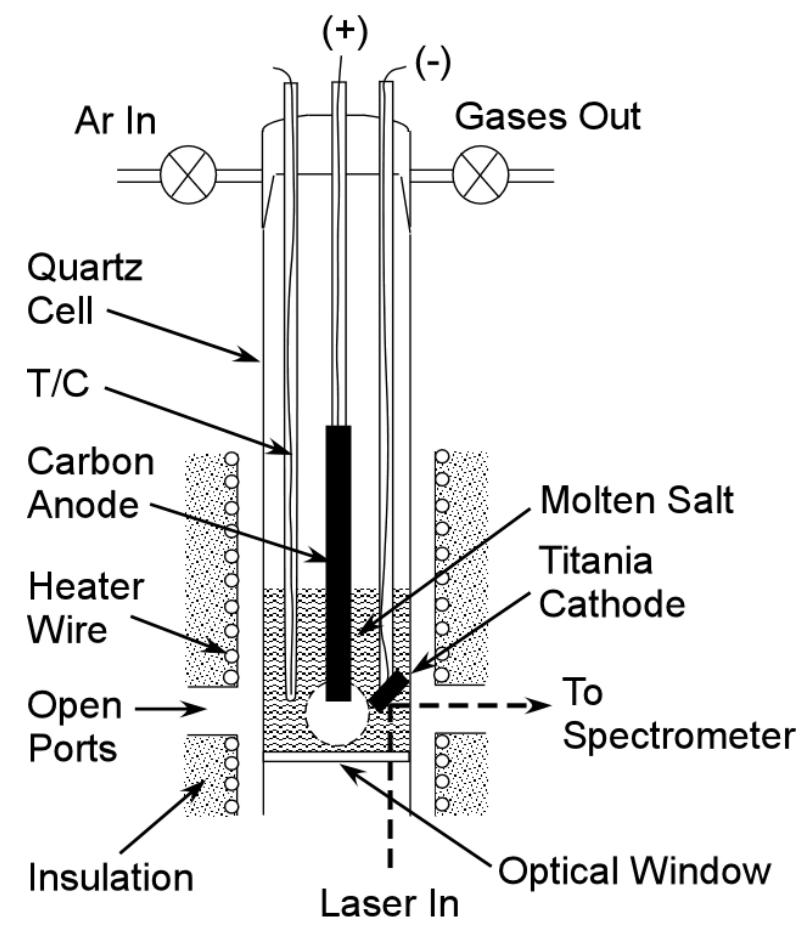

Fig. 1. Diagram of Raman Cell 

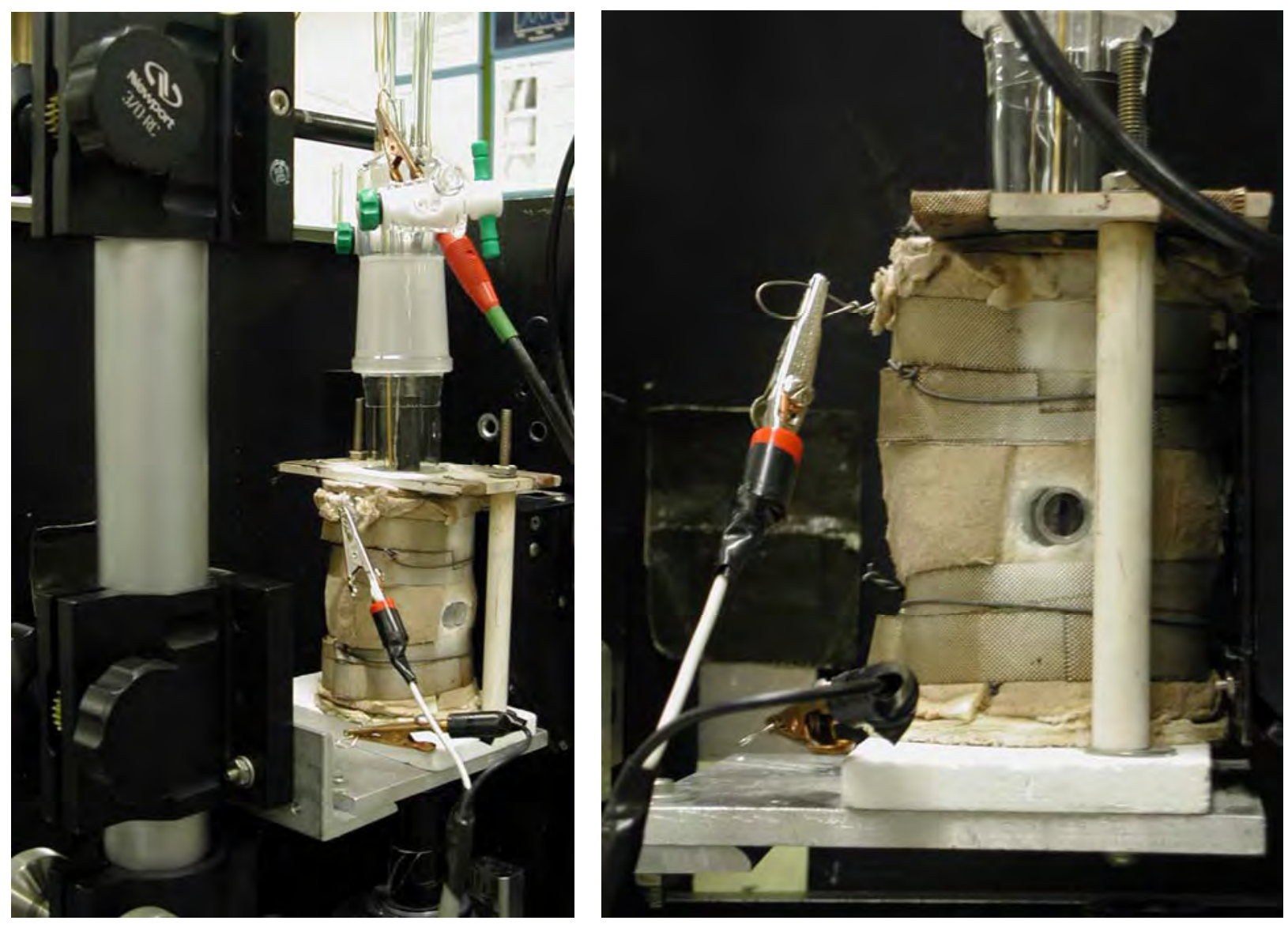

Fig. 2. Photos of Raman Cell

The cell was used for three types of studies and the cell was used in slightly different ways in each case as described below:

Type 1: Measurements on the unpolarized titania cathode. These studies used only the thermocouple and the titania sample. Measurements were taken as a function of temperature outside of the molten salt and inside of the molten salt at $900^{\circ} \mathrm{C}$.

Type 2: Measurements on the molten salt. These studies also used the titania sample as a scattering surface to facilitate focusing and alignment but analysis focused on the spectrum of the salt. The temperature of all the melts studies was $900^{\circ} \mathrm{C}+/-5^{\circ} \mathrm{C}$

Type 3: Measurements on polarized electrodes. These studies used the cell with both electrodes in place. Scattering was attempted off both the titania cathode and carbon anode in the melt at $900^{\circ} \mathrm{C}$. 


\subsection{Materials}

As described above, experiments were performed using titania samples supplied by TIMET, Inc. as the "cathode material" and POCO graphite as the "anode material." The titania samples were of two types: unreduced (white, very resistive) and reduced (black, electrically conductive). The reduced samples exhibited no Raman spectra under any of the conditions tested so they could not be used to study cathode chemistry. Consequently, the unreduced samples were used to study the titantia chemistry. Measurements were obtained on the unreduced titania in air as a function of temperature and within the melt at $900^{\circ} \mathrm{C}$. The reduced titania was used as the cathode material to supply current when the cell was assembled to do electrochemical studies near the carbon anode.

The $\mathrm{CaCl}_{2}, \mathrm{CaO}$ and metallic $\mathrm{Ca}$ used to make up the molten salt compositions were supplied by TIMET, Inc. TIMET obtained the $\mathrm{CaCl}_{2}$ from Tetra International Express, Inc. In most cases, molten mixtures were made by mixing components at room temperature and then melting. During some composition studies (e.g. CaO), however, components were added directly to the melt at temperature and then the melt was briefly stirred with a quartz rod.

The $\mathrm{CaCl}_{2}$ was dried at $300^{\circ} \mathrm{C}$ for approximately $16 \mathrm{~h}$, then transferred to the cell under Ar. Although melting was performed under a flowing Ar stream, some adjustment of sample or electrode position was required during the spectroscopic measurements to align the sample. In some cases, the cell cap had to be removed and new components inserted. Unfortunately, this introduced air into the cell, so none of the experiments were performed with total exclusion of air or water vapor. Other than the obvious ramifications discussed below, the effects of this reexposure to air and water vapor are uncertain.

\subsection{Instrumentation}

The pulse-gating Raman spectroscopy setup is shown in Fig. 3. It used a Spectra Physics (Mountain View, CA) Quanta-Ray GCR-5 pulsed Nd:YAG laser with the following characteristics:

Wavelength: $532 \mathrm{~nm}$ (frequency-doubled emission)

Pulse frequency: $30 \mathrm{~Hz}$

Pulse width: 10 ns

Laser Power: $2-20 \mathrm{~mW}$ (most experiments at 2-5 $\mathrm{mW}$ )

Pulse Energy: $67-670 \mu \mathrm{J} /$ pulse

A Spex Model 1877 0.6-m Triple Spectrometer (JY, Inc., Edison, NJ) was used for spectral analysis with a Princeton Instruments (Trenton, NJ) Model ICCD-1024-MC-E/I 
gated intensified CCD detector. The detector gate was synchronized to the laser pulse using a Princeton Instruments Model PG-200 programmable pulse generator and the electronic signal output of the laser to time the acquisition. The gating pulse was $40 \mathrm{~nm}$ in width and the delay was set at $120 \mathrm{~s}$ relative to the laser signal. Spectrometer settings were as follows:

External Slit Width: $100 \mu \mathrm{m}$

Acquisition Time: $10-100 \mathrm{~s}$

Spectra Range: The lowest measurable Raman shift was a $91 \mathrm{~cm}^{-1}$ using our setup.

The range for low-frequency measurements was $91-800 \mathrm{~cm}^{-1}$. Measurements on $\mathrm{CO}_{2}$ required setting the monochromator to higher frequencies. The spectral range for this setting was $868-1481 \mathrm{~cm}^{-1}$.

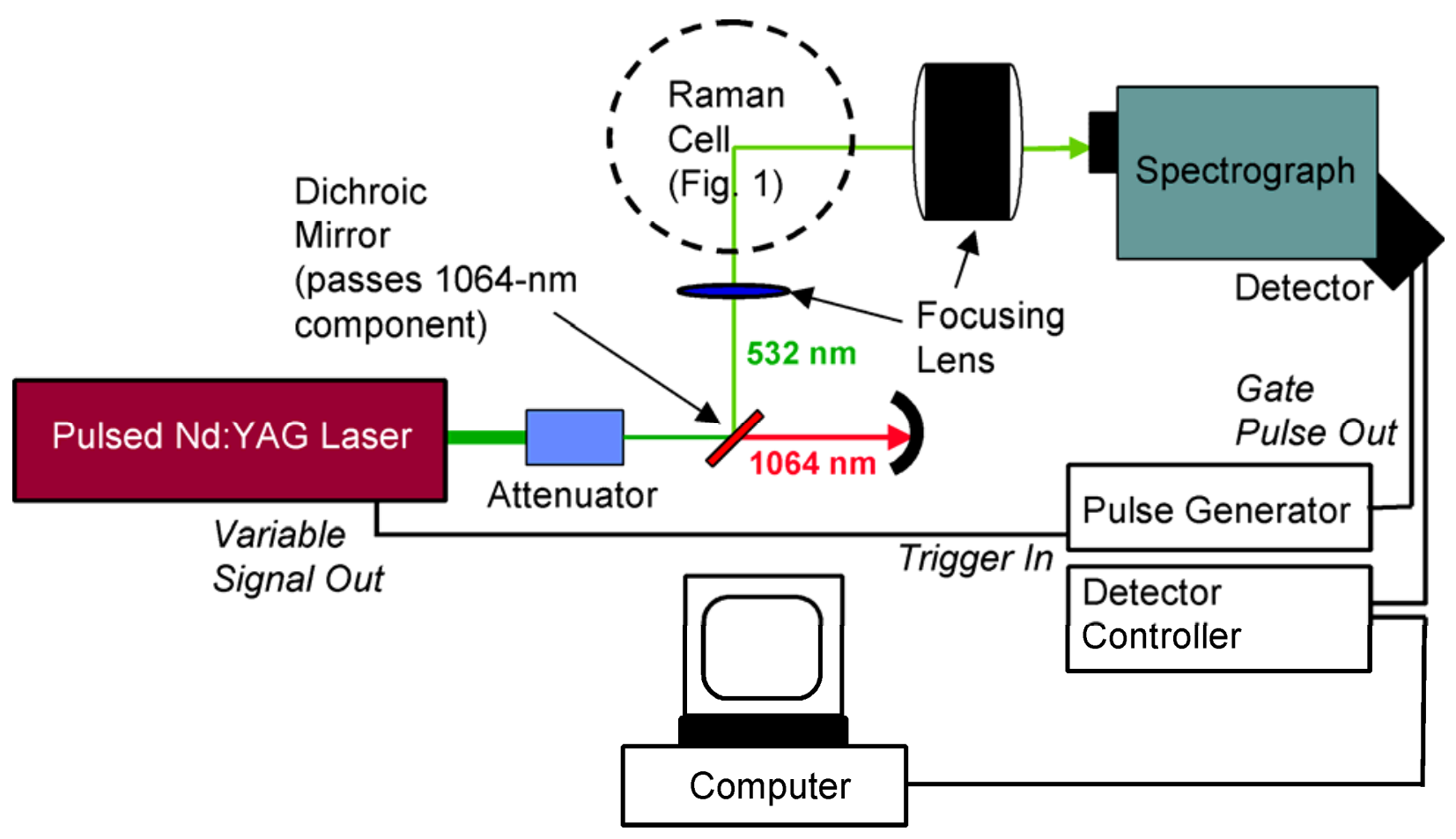

Fig. 3. Typical Raman Spectroscopy Setup Using Pulse-Gating 


\subsection{Results and Discussion}

\subsection{Pulse-Gating Performance}

The pulse-gating setup used in this work reduced black-body emission signals from a million counts to almost nothing. Careful adjustment of the width and delay of the gate pulse was required and accomplished successfully by observing the spectrum of rutile $\mathrm{TiO}_{2}$ (samples provided by TIMET) until the Raman bands were strongest and background was negligible. Fig. 4 shows the extent of suppression of the black-body emission from the furnace alone at $900^{\circ} \mathrm{C}$ with the monochromator set to give the indicated Raman-shift range using 532-nm excitation.

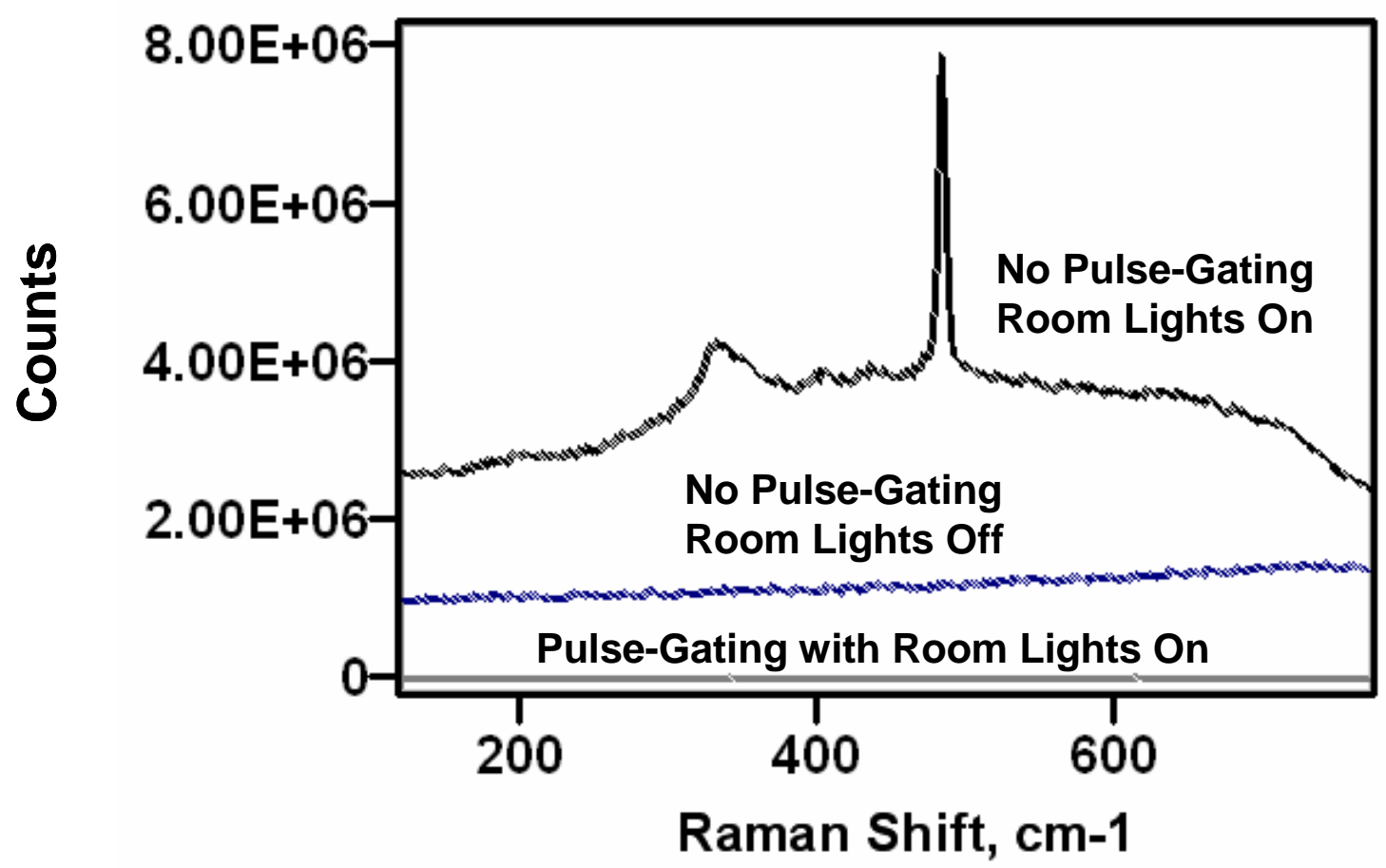

Fig. 4. Spectrum of Furnace at $900^{\circ} \mathrm{C}$ with and without Pulse-Gating. Contributions from both black-body emission and room lights are shown. 


\subsection{Molten $\mathrm{CaCl}_{2}$}

Raman spectra of the molten $\mathrm{CaCl}_{2}$ salt (as well as the molten salt solutions described later) were obtained using a $90^{\circ}$ scattering configuration, as shown in Fig. 1. To facilitate aligning and focusing, the beam was scattered off of a titania substrate oriented at $45^{\circ}$ relative to the incident beam. The titania substrate was a sample of the TIMET cathode material, which was determined to be rutile as described below. Consequently, all spectra of the molten salts contain the spectrum of rutile also.

Fig. 5 shows the spectrum of molten $\mathrm{CaCl}_{2}$ at $900^{\circ} \mathrm{C}$. There are two things to note about the conditions under which this spectrum was obtained. First, there are actually two spectra of the same salt, each obtained under two different polarization configurations. In the $\mathrm{HH}$ configuration, the incident beam is polarized in the $y z$ plane and the scattered light is measured in the $x z$ plane (both polarization vectors perpendicular to the paper). In the HV configuration, the incident light is also polarized in the $y z$ plane but the scattered light is measured in the xy plane (in the plane of the paper). The polarization direction of the incident beam is set by the laser, whereas the polarization direction of the scattered light is controlled by a Polaroid film positioned between the sample and the slit of the spectrograph. The reason that spectra were obtained under different polarization conditions is that "unpolarized" i.e. collected without the Polaroid film and also obtainable from summing the two spectra shown, are reported to show less information on molten salt structure $[3,5]$. This was supported by spectra we obtained under unpolarized conditions as well (not shown). The second characteristic to note is that the spectra shown in Fig. 5 are plotting in terms of "unreduced" Raman intensities. The relative intensity of Raman bands is strongly influenced by temperature due to frequency-and-temperature-dependent coupling between the incident light and the vibrational mode. The effect must be removed from the spectra in studies were temperature comparisons are made. Several strategies for doing this are possible. The one we chose here was to convert the Raman intensities into the "reduced" form using the following equations:

$$
\mathrm{I}_{\text {Reduced }}(\bar{v}, T)=\left[\frac{\bar{v}}{\mathrm{n}(\bar{v})+1}\right] \cdot \mathrm{I}_{\text {Unreduced }}(\bar{v})
$$

where

$$
\mathrm{n}(\bar{v})=\left[\exp \left(\frac{\mathrm{hc} \bar{v}}{\mathrm{kT}}\right)-1\right]^{-1}
$$

and $\bar{V}$ is the Raman shift, $\mathrm{T}$ is the absolute temperature, $\mathrm{h}$ is Planck's constant, $\mathrm{c}$ is the speed of light, $k$ is Boltzmann's constant and $n(\bar{V})$, given by Equation (2) is known as 
the Bose-Einstein population factor. The spectra in Fig. 5 are not corrected for temperature. Fig. 6 shows the same two spectra corrected for temperature using Equations (1) and (2). As shown in Fig. 2, the main effect of the correction is to reduce the contribution from background at lower frequencies.

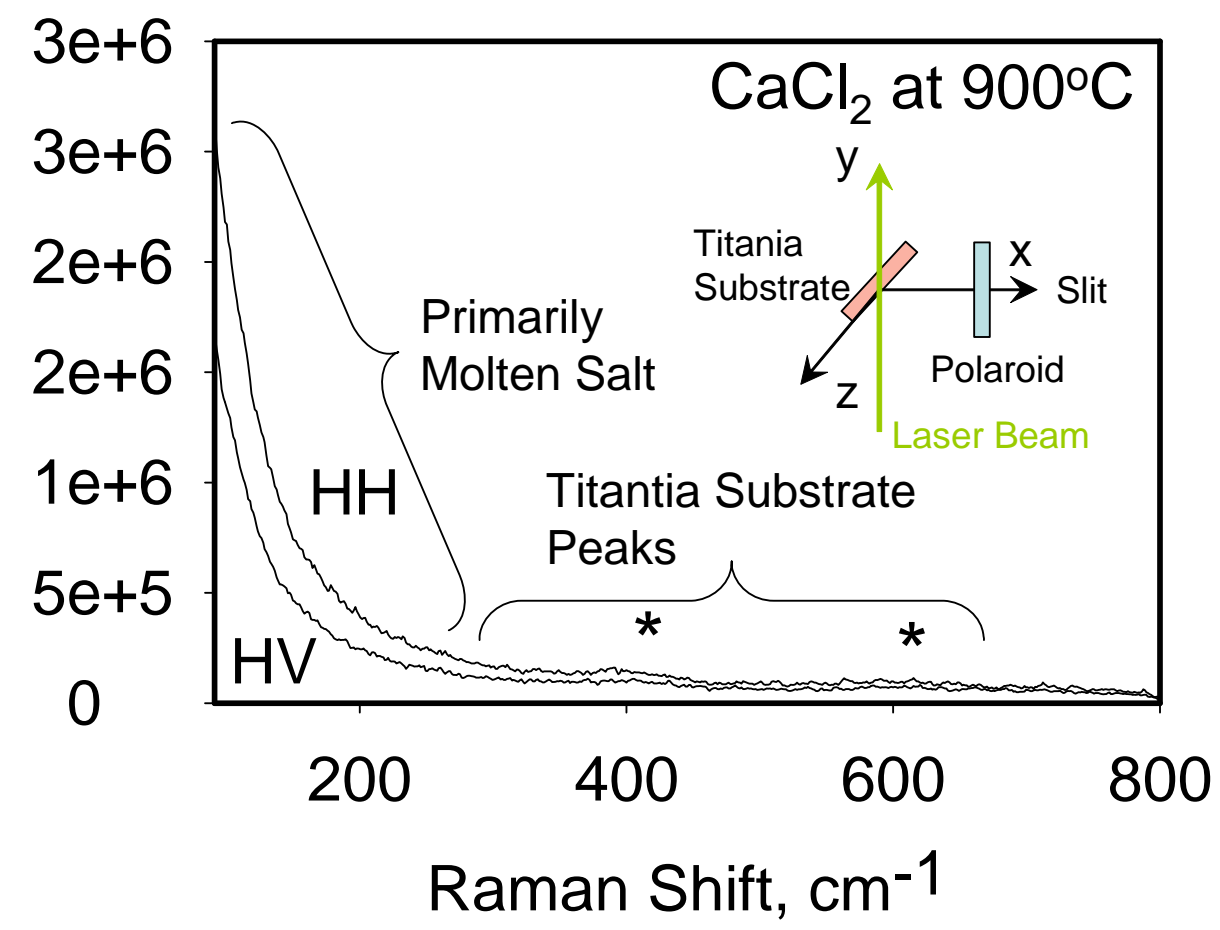

Fig. 5. Raman Spectrum of Molten $\mathrm{CaCl}_{2}$ at $900^{\circ} \mathrm{C}$ under Two Polarization Conditions. Intensities are not corrected for temperature. The spectrum shows two regions: (1) low frequency region containing information on the molten salt and (2) higher frequency region exhibiting bands from the substrate.

As shown in Fig. 5, the unpolarized spectra of molten $\mathrm{CaCl}_{2}$ is characterized by a broad "tail" that decreases in intensity from the exciting line (zero Raman shift) to approximately $350 \mathrm{~cm}^{-1}$. (The peaks marked with an asterisk above $250 \mathrm{~cm}^{-1}$ are due to the rutile substrate.) This tail arises from the scattering phenomena involving longwavelength collective oscillations in the molten salt medium. Similar spectra have been obtained for the molten alkali halides $[3,5]$ and the results have been associated with periodic oscillations of both charge and mass (density) within the liquid. Neither the $\mathrm{HH}$ nor the HV spectrum exhibits resolved bands that can be assigned to the localized vibration of a molecular unit. This is in contrast to the spectrum of molten $\mathrm{MgCl}_{2}$ that exhibits a relatively strong band at $205 \mathrm{~cm}^{-1}$ assigned to the symmetric stretch of the $\mathrm{MgCl}_{4}{ }^{2-}$ complex. Moreover, the reduce Raman spectra shown in Fig. 6 shows that correcting the spectra for temperature in this spectral range does not reveal any hidden 
bands. This means that the structure of molten $\mathrm{CaCl}_{2}$ is more disordered than $\mathrm{MgCl}_{2}$. There are no distinct calcium chloride complexes, analogous to $\mathrm{MgCl}_{4}{ }^{2-}$. The only structure that appears to exist is a more-or-less regular spatial distribution of positive and negative charge, along with $\mathrm{Ca}$ and $\mathrm{Cl}$ ions, similar to that dictated by the DebyeHuckel formalism for aqueous solutions. Oscillations of this charge/mass framework occur at low frequency and give rise to the tail near the excitation line. This result is discouraging in regard to the utility of using Raman spectroscopy to monitor melt chemistry during electrolysis. No chemical markers occur in the spectrum of molten $\mathrm{CaCl}_{2}$ and, unless new features appear in the spectrum as a result of varying composition, there will be no way to use the technique to follow chemistry as cell conditions are changed.

Fig. 6 also shows the result of plotting the depolarization ratio of the polarized spectra versus Raman shift. The depolarization ratio is defined as the result of dividing the Raman intensity measured in the HV configuration by the Raman intensity in the $\mathrm{HH}$ configuration. Theory predicts [8] that this quotient is relatively high, approaching 0.75 , for spectral features arising from non-symmetric vibrations while it is much smaller for bands due to the symmetric vibration of symmetric molecules or complexes like the tetrahedral $\mathrm{MgCl}_{4}{ }^{2-}$ species [7]. As shown in Fig. 6, the depolarization ration is relatively constant, above 0.6 , throughout the low-frequency spectral range studied. This indicates, much as the reduced Raman spectra shown in the same Figure, that there are no bands hidden in the background than can be associated with a $\mathrm{Ca}$ analog to $\mathrm{MgCl}_{4}{ }^{2-}$. 

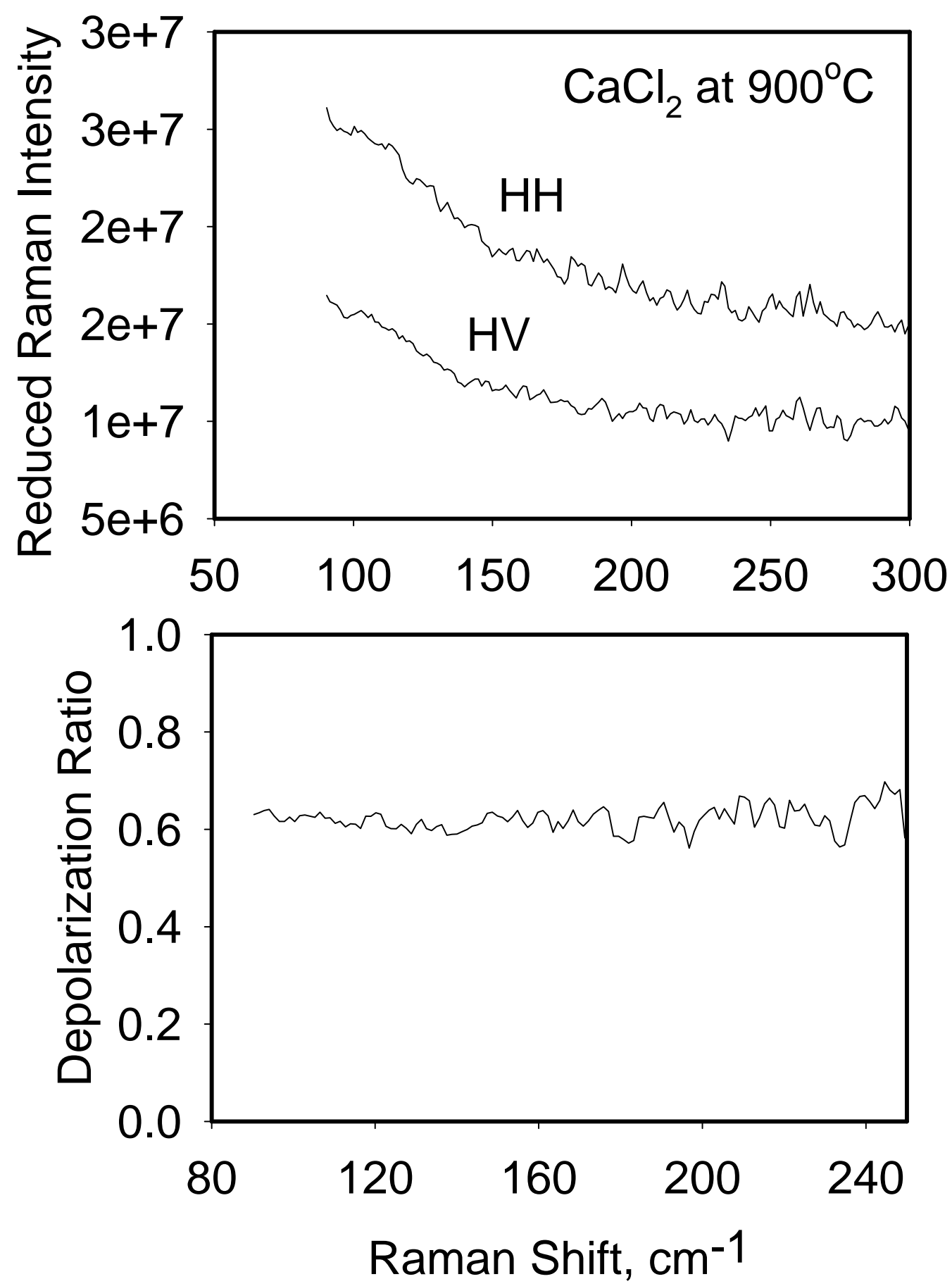

Fig. 6. Reduced Polarized Raman Spectra and Depolarization Ratio for Molten $\mathrm{CaCl}_{2}$ at $900^{\circ} \mathrm{C}$. 


\subsection{Effects of $\mathrm{CaO}$ and $\mathrm{Ca}$ Addition}

The reduced polarized Raman spectra of molten $\mathrm{CaCl}_{2}$ at $900^{\circ} \mathrm{C}$ containing $1 \%$ (wt. \%) and $2 \% \mathrm{CaO}$ are shown in Figs. 7 and 8 . Results of adding $1 \% \mathrm{Ca}$ metal to a solution of $\mathrm{CaCl}_{2}$ plus $1 \% \mathrm{CaO}$ are shown in Fig. 9. The principal impact on the spectra is that the overall intensity decreases with larger additions of both $\mathrm{CaO}$ and $\mathrm{Ca}$. This can be attributed to the loss of signal due to diffuse scattering from particles in the melt. As $\mathrm{CaO}$ and especially $\mathrm{Ca}$ are added, not all of the components dissolve so that some of the laser light scatters diffusely. This contributes to lower measured Raman intensities. However, none of the spectra exhibit any new spectral features and no significant changes occur in the functional form of the low-frequency tail as the chemicals are added, indicating that no new dissolved Raman-active chemical complexes are formed at measurable concentrations. In conclusion, either the concentrations are too low to be detected or the role of the added chemicals is to "join" the relatively disorganized structure of the $\mathrm{CaCl}_{2}$ ionic environment in a more-or-less random manner rather than form complexes whose vibrations are decoupled from the media network.

The depolarization ratios are also plotted for each set of polarized Raman spectra in Figs. 7 through 9. As shown, the curves are very flat up to $350 \mathrm{~cm}^{-1}$ and exhibit relatively large values, approximately 0.5 or higher. If a polarized band was present in this region, then there should have been some indication of a "negative" dip (lower depolarization ratio) in the curves. This result supports the conclusion that, unlike molten $\mathrm{MgCl}_{2}, \mathrm{CaCl}_{2}$ does not form symmetric complexes in the melt that would have been expected to give rise to a symmetric stretch in this region. The value of the depolarization ratio increases in going from Fig. 7-9. This may indicate the added components do perturb the structure of the melt in some way, perhaps altering the localized distribution of charge around counter-ions. This might be expected to affect the oscillation of charge, for example, during low-frequency excitation. However, it is also possible that the physical properties of the molten salt caused this trend. As more solids were added, there was more diffuse scattering from undissolved particles. Depending on the details of this scattering, it may be that the intensity for one polarization condition was affected more by the loss of signal than the other. This could cause the depolarization ratio "background" to vary from one composition to another.

Finally, the results from the experiment concerning Ca additions (Fig. 9) demonstrates that it was also not possible to resolve the contribution of dissolved "metallic" species containing $\mathrm{Ca}$, analogous to $\mathrm{Mg}_{2}{ }^{+}$, that has been observed in $\mathrm{MgCl}_{2}$ melts. This metallic species was reported to give rise to a peak around $125 \mathrm{~cm}^{-1}$. We found no strong evidence for this (for a $\mathrm{Ca}_{2}{ }^{+}$analog) in the case of $\mathrm{CaCl}_{2}$ melts at concentrations of added Ca metal up to 1\%, allowing about an hour for dissolution. Reasons for this include: too low a concentration of dissolved metal, not enough time for dissolution, insufficient sensitive of our setup, or, possibly, the fact that the vibrational frequency, expected to be lower for the $\mathrm{Ca}-\mathrm{Ca}$ bond than for the $\mathrm{Mg}-\mathrm{Mg}$ bond, was lower than 91 $\mathrm{cm}^{-1}$ (the lower cutoff frequency for measurements in this work). 


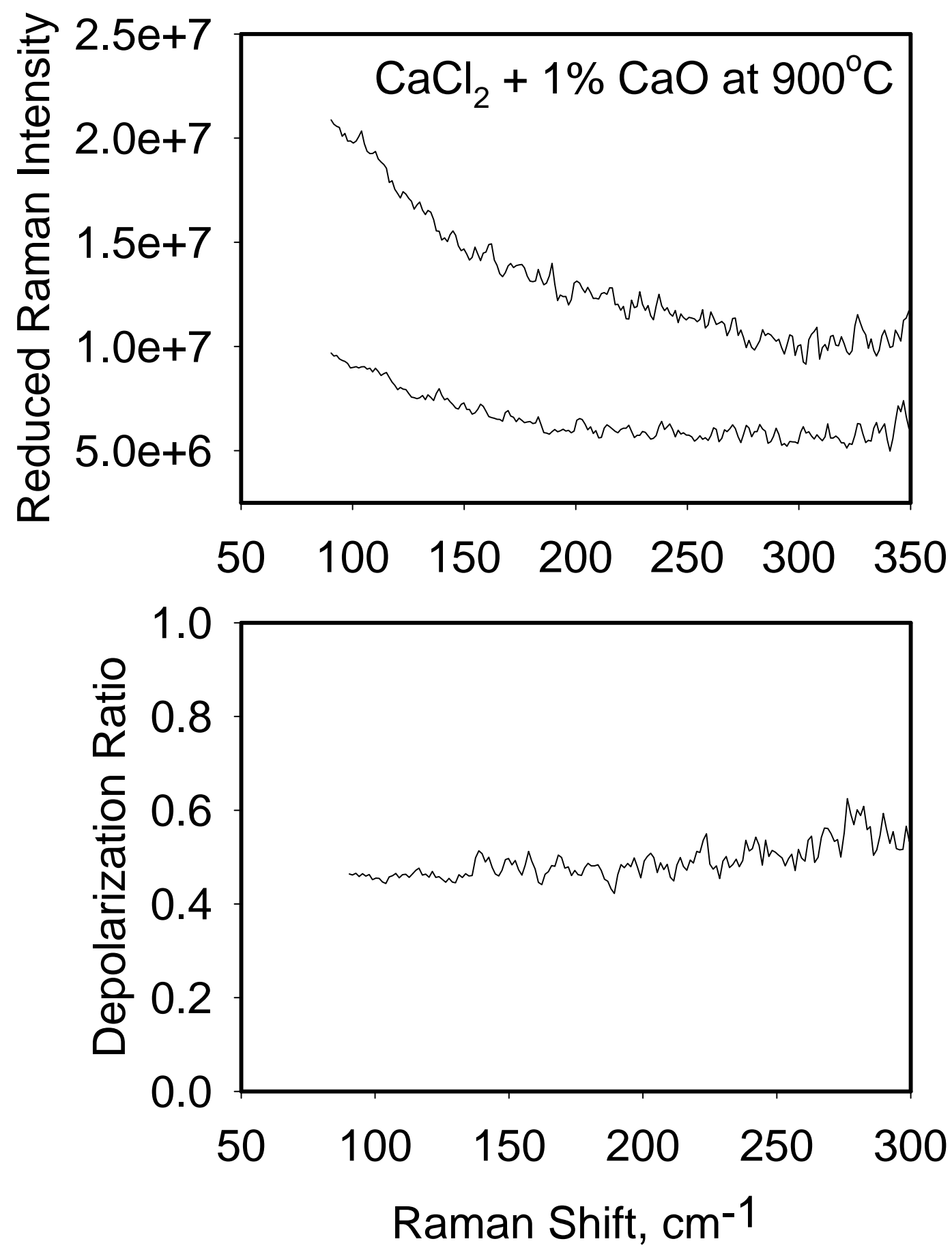

Fig. 7. Reduced Polarized Raman Spectra and Depolarization Ratio for Molten $\mathrm{CaCl}_{2}$ Containing $1 \% \mathrm{CaO}$ at $900^{\circ} \mathrm{C}$. 

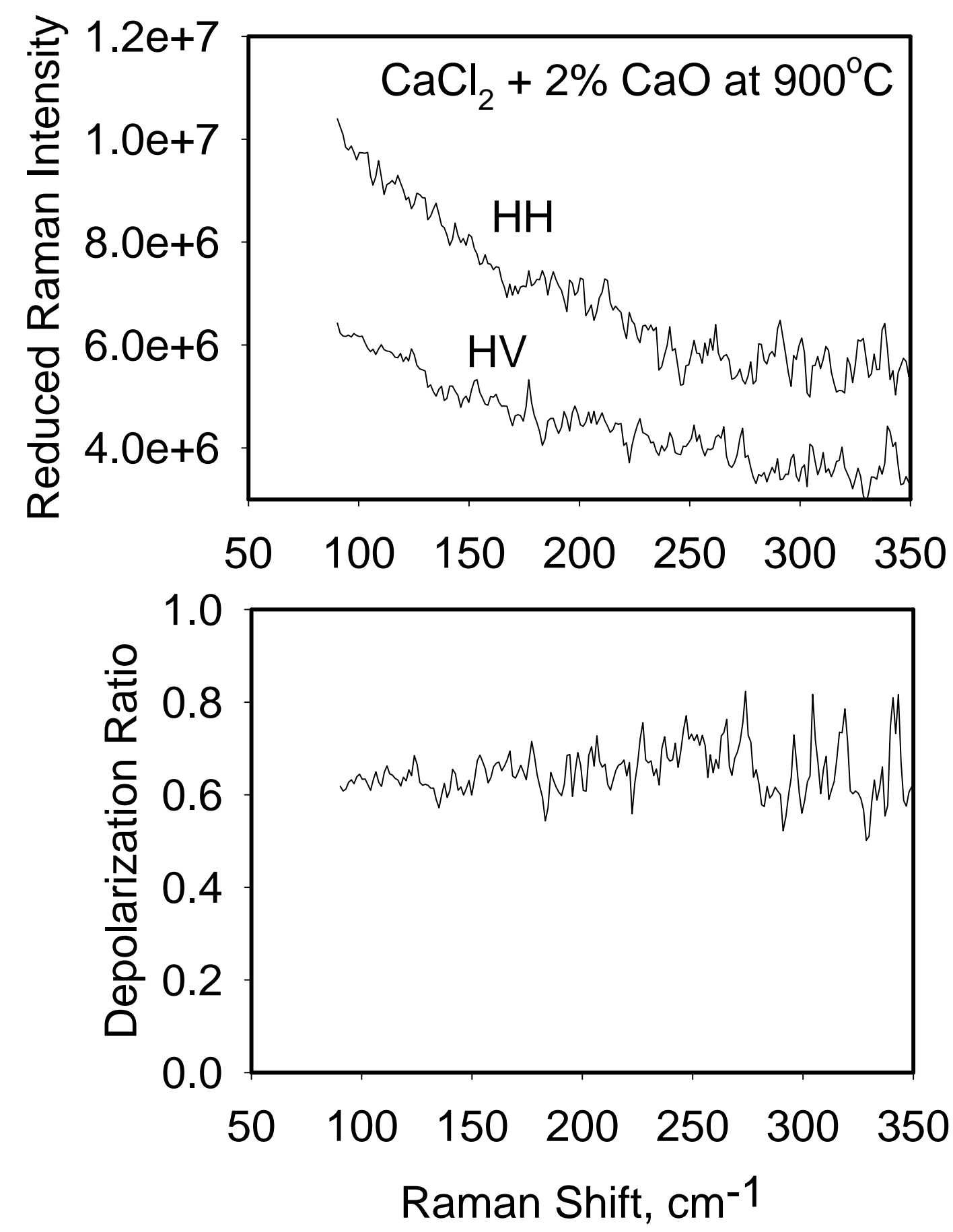

Fig. 8. Reduced Polarized Raman Spectra and Depolarization Ratio for Molten $\mathrm{CaCl}_{2}$ Containing $2 \% \mathrm{CaO}$ at $900^{\circ} \mathrm{C}$. 

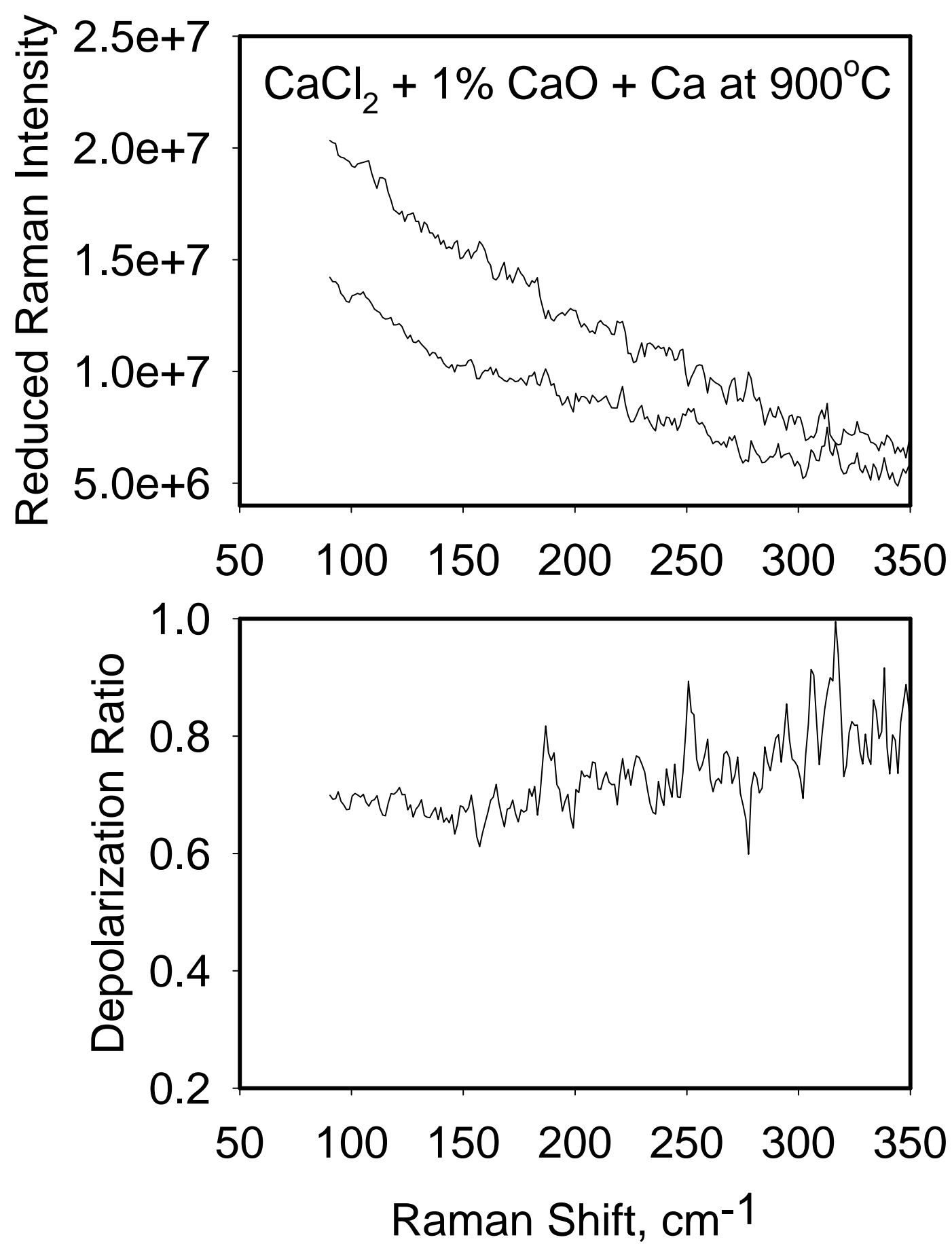

Fig. 9. Reduced Polarized Raman Spectra and Depolarization Ratio for Molten $\mathrm{CaCl}_{2}$ Containing $1 \% \mathrm{CaO}$ and $1 \% \mathrm{Ca}$ Metal at $900^{\circ} \mathrm{C}$. 
Inspection of the TIMET titantia substrate (never electrically polarized) after it was removed from the melt containing Ca metal revealed that the formerly white, unreduced, rutile had turned black. This was not observed when metallic Ca was not present. We believe the black reaction product is Ti metal and/or partly reduced rutile formed as a result of direct reaction between the Ca metal (probably in dissolved form) and the unreduced (originally white) rutile. Attempts to obtain a Raman spectrum of the black material were unsuccessful, which is consistent with either the formation of Ti metal or partial reduction of the rutile. These products would have no or very weak Raman signals.

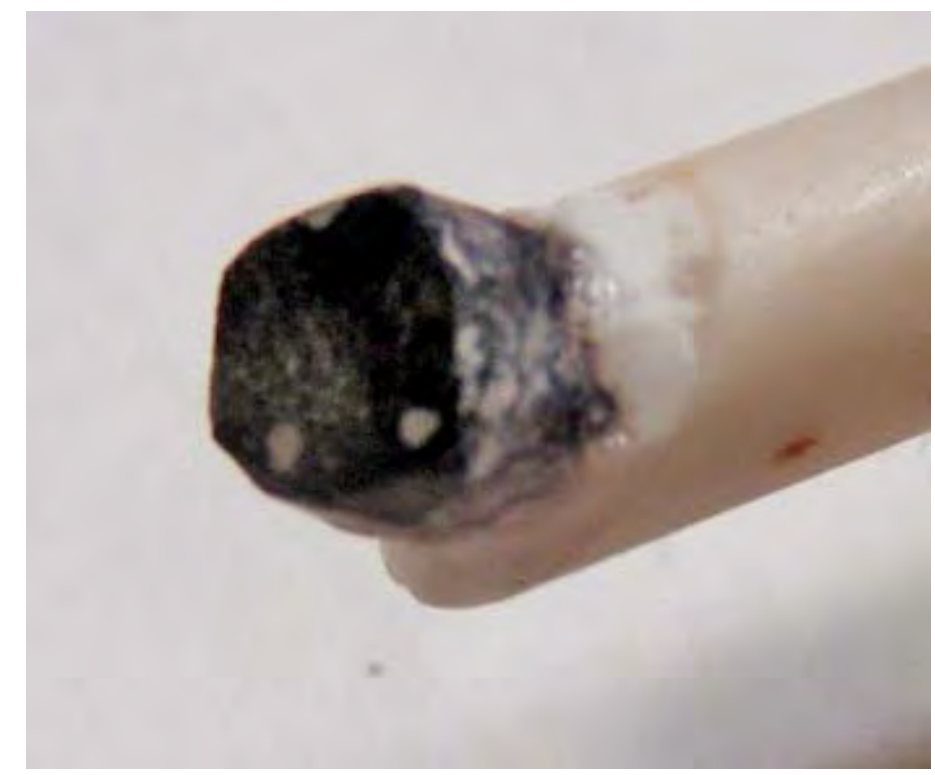

Fig. 10. TIMET Titania Cathode Material (Formerly Unreduced) after Exposure to $\mathrm{CaCl}_{2}$ Melt at $900^{\circ} \mathrm{C}$ Containing $1 \%$ Ca Metal.

\subsection{Effects of $\mathrm{CO}_{2}$}

Experiments were performed in an attempt to identify both dissolved $\mathrm{CO}_{2}$ and carbonate ions in molten $\mathrm{CaCl}_{2}$ at $900^{\circ} \mathrm{C}$ and 1 bar total pressure. The spectral region chosen for this work was between $868 \mathrm{~cm}^{-1}$ and $1481 \mathrm{~cm}^{-1}$. Carbonate melts are known to give rise to a strong sharp band at approximately $1061 \mathrm{~cm}^{-1}$ due to the symmetric stretch of the carbonate ion. Gaseous carbon dioxide is known to have its strongest band at 1388 $\mathrm{cm}^{-1}$ (at room temperature). Even with shifts due to differences in temperature and ionic environment, the spectral range chosen should have been adequate to discern contributions from both of these components.

Two different tests were conducted. In the first, $\mathrm{CaCO}_{3}$ was added directly to the melt at $900^{\circ} \mathrm{C}$. The carbonate was observed to decompose into $\mathrm{CO}_{2}$, evidenced by vigorous 
bubbling, and, presumably, $\mathrm{CaO}$. Given the amount of $\mathrm{CaCO}_{3}$ added, approximately $1 \%$, and the amount, vigor and size of the $\mathrm{CO}_{2}$ bubbles formed, it was assumed that this test effectively saturated the melt with $\mathrm{CO}_{2}$. Moreover, an additional $1 \% \mathrm{CaO}$ was also added to the melt to increase solubility. Based on work by Maeda and McLean [9], it is estimated that approximately $1 \% \mathrm{CO}_{2}$ was dissolved in the melt in this experiment and that only $0.01 \%$ (of the total weight) remained as carbonate. In the second test, an electrolysis cell was set up, using a reduced TIMET titania cathode and a graphite anode. Both electrodes were completely submerged in the melt. The bottom surface of the graphite cathode was beveled at $45^{\circ}$ and the incident laser beam was made to scatter off of it and into the spectrograph. Using this arrangement, spectra were collected from the vicinity of the graphite anode while applying $0.1 \mathrm{~A}$ of anodic current (which required approximately $2 \mathrm{~V}$ in our cell). Many fine carbon dioxide bubbles were being produced at the anode during spectral acquisition.

None of the spectra collected in these experiments gave any indication of significant amounts of either carbonate ions or dissolved carbon dioxide. For example, Fig. 11 shows a spectrum obtained from the vicinity of the carbon anode during electrolysis in molten $\mathrm{CaCl}_{2}+1 \% \mathrm{CaO}$ at $900^{\circ} \mathrm{C}$ and $0.1 \mathrm{~A}$ current. No peaks are unambiguously assignable in this spectrum. A feature near $1360 \mathrm{~cm}^{-1}$ may be due to carbon dioxide, but the intensity is comparable to other noise in the spectrum so its assignment is uncertain. Apparently, the concentrations of carbonate and dissolved carbon dioxide are below the detection limit for our setup. A pressurized cell may be necessary to attain sufficient concentration of dissolved $\mathrm{CO}_{2}$ to be observed.

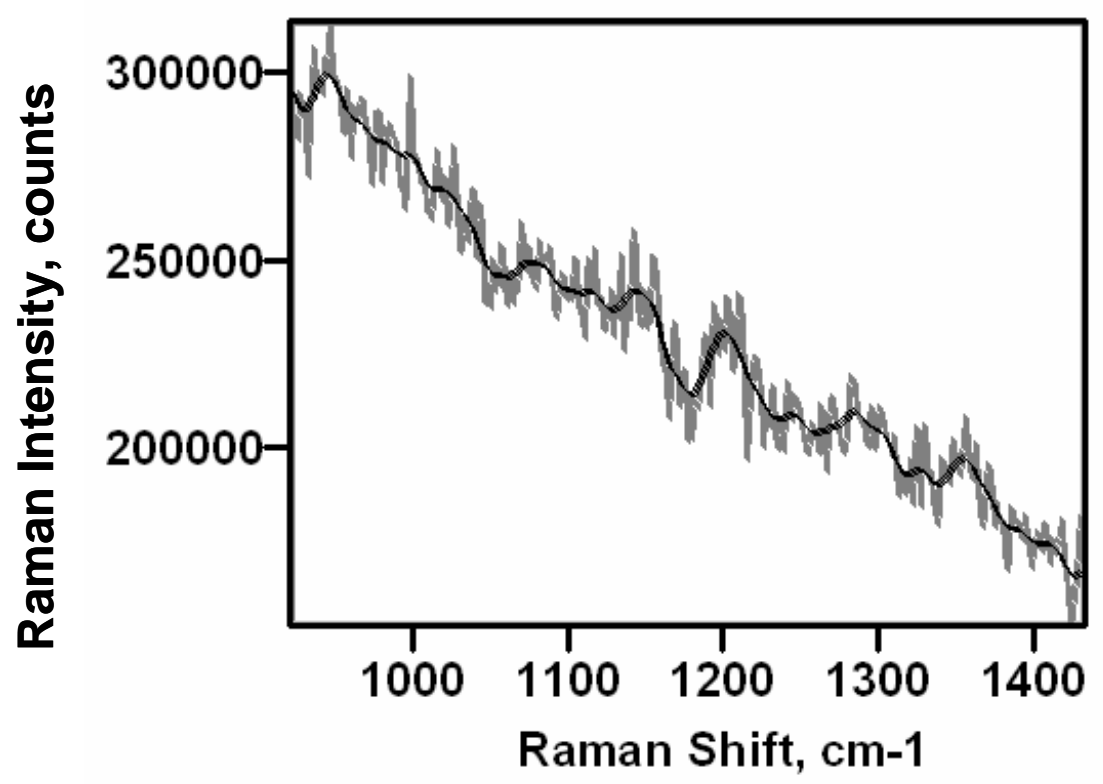

Fig. 11. TIMET Titania Cathode Material (Formerly Unreduced) after Exposure to $\mathrm{CaCl}_{2}$ Melt at $900^{\circ} \mathrm{C}$ Containing $1 \%$ Ca Metal 


\subsection{TIMET Cathode Material}

Spectra of the TIMET cathode materials were obtained as a function of temperature both outside the molten $\mathrm{CaCl}_{2}$ salt and submerged within it. As shown in Fig. 12, the unreduced (white) form of the material gives rise to a Raman spectrum in air at $25^{\circ} \mathrm{C}$ that contained three clearly resolved peaks at 230,448 and $610 \mathrm{~cm}^{-1}$. This spectrum corresponds to that of the rutile phase of $\mathrm{TiO}_{2}$. The reduced (black) form of the material, on the other hand, gave no detectable Raman bands under the same conditions. This is not unexpected since dark materials that are electronically conducting usually give weak, if any, Raman spectra.

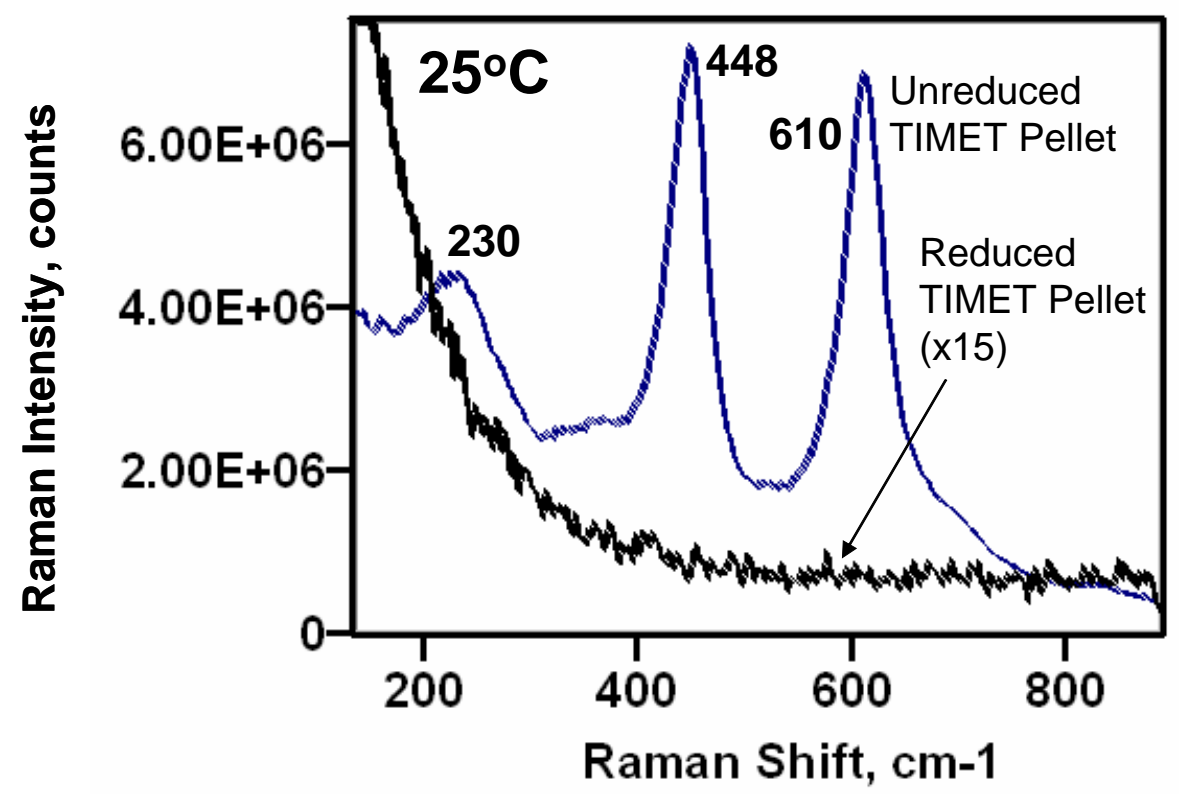

Fig. 12. Raman Spectra TIMET Titania Cathode Materials in Air at $25^{\circ} \mathrm{C}$. Intensities for the reduced material were multiplied by a factor of 15 .

Raman spectra of the unreduced rutile samples obtained as a function of temperature in air are shown in Fig. 13. The strongest Raman peaks, originally at 448 and $610 \mathrm{~cm}^{-1}$, are observed to decrease in intensity, broaden and shift to lower frequency. The behavior of the weaker peak at $251 \mathrm{~cm}^{-1}$ is uncertain. Notice that the background goes down with decreasing frequency when the intensities are plotted in the temperaturereduced form. This confirms the statements made in an early Section that signal intensity below $350 \mathrm{~cm}^{-1}$ measured from melts containing a titanium scattering substrate arises primarily from the melt itself. 


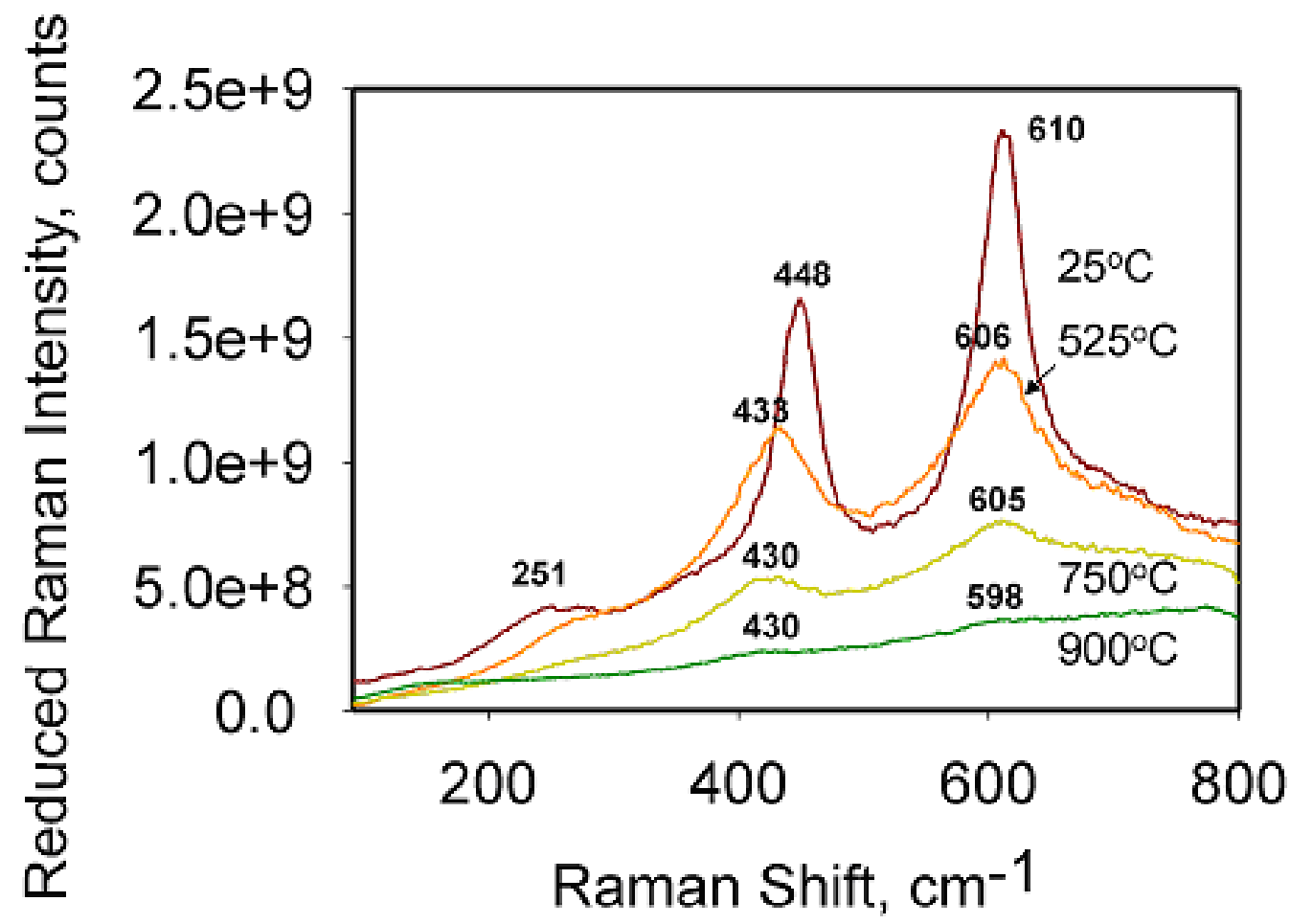

Fig. 13. Raman Spectra of TIMET Titania Cathode Material (Unreduced Form) as a Function of Temperature in Air. The Raman intensities are temperature-reduced.

Raman spectra of the unreduced TIMET titania cathode material were also obtained while submerged in molten $\mathrm{CaCl}_{2}$ at $900^{\circ} \mathrm{C}$. Fig. 14 shows spectra collected from three different samples in the melt at three different times. The spectrum labeled "In Melt \#1" was collected with the monochromator filter stage set to attenuate intensities below 150 $\mathrm{cm}^{-1}$. This has the effect of enhancing sensitivity to the rutile peaks as shown. Spectra labeled "In Melt \#2" and "In Melt \#3" (and also "Out of the Melt") were collected with the filter stage adjusted to allow more signal from lower frequencies (down to $91 \mathrm{~cm}^{-1}$ ) to reach the detector. This increased sensitivity to the lower frequencies where moltensalt information was expected to occur (Fig. 5) but, as illustrated in Fig. 14, also reduced the $S / N$ for the rutile bands at higher frequency. As shown in Fig. 14, the rutile peaks observed in spectra obtained with the material out of the melt and submerged within it were sufficiently alike to conclude that the material was reasonably stable in contact with the melt for the duration of these experiments, i.e. several hours. 


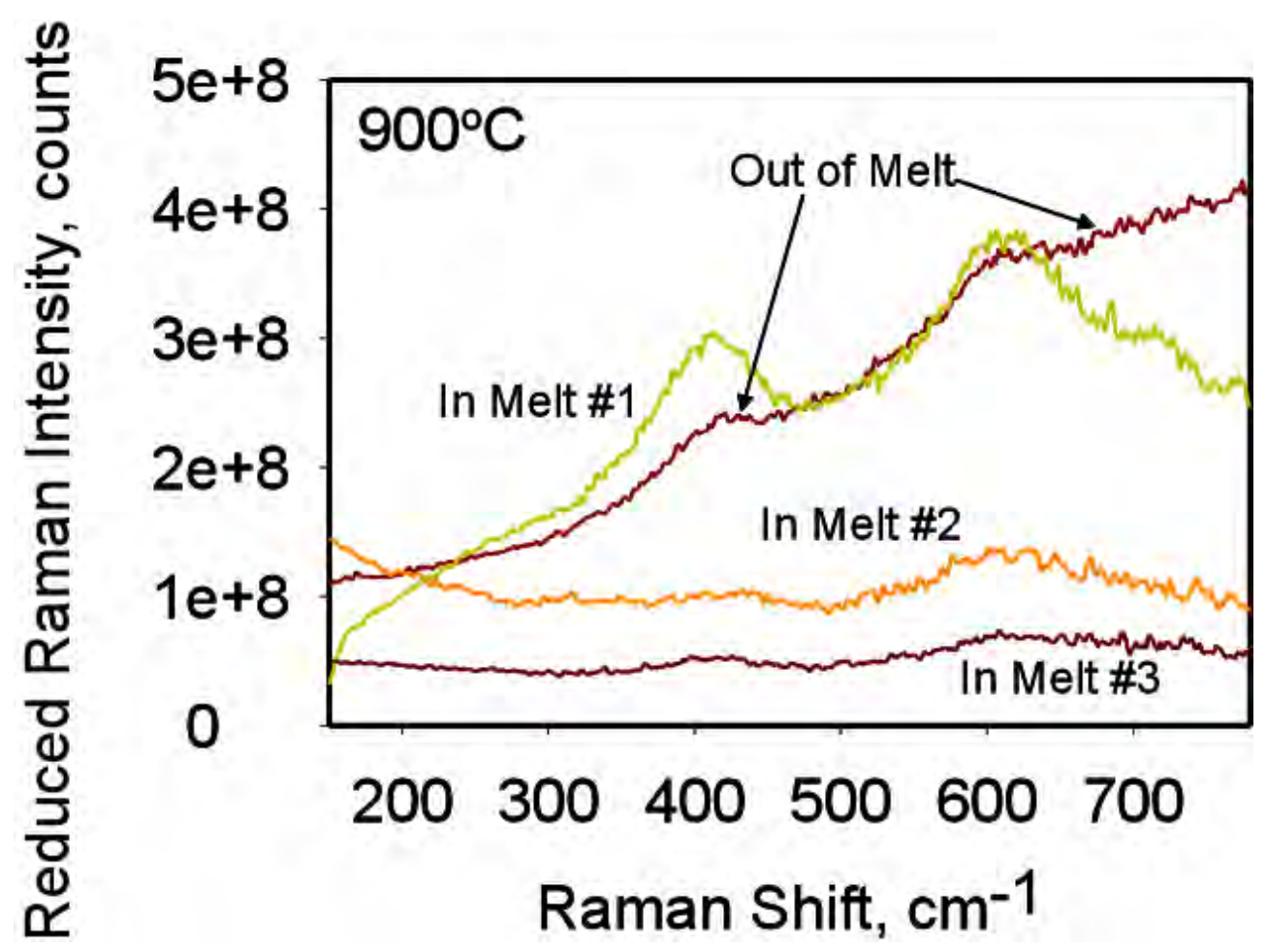

Fig. 14. Raman Spectra of TIMET Titania Cathode Material (Unreduced Form) Submerged in Molten $\mathrm{CaCl}_{2}$ at $900^{\circ} \mathrm{C}$. A spectrum of the material at the same temperature in air is shown for comparison.

Attempts were also made to obtain spectra from the titania cathode during electrochemical reduction in $\mathrm{CaCl}_{2}$ melt containing $1 \% \mathrm{CaO}$ at $900^{\circ} \mathrm{C}$ under conditions similar to those described for the $\mathrm{CO}_{2}$ studies above. Once electrolysis commenced, it was very difficult to measure any Raman signal at all from the cathode, consistent with a reduced form of the titania being favored under these conditions and the much smaller Raman scattering cross-section of the reduced material.

Despite the difficulty in obtaining Raman spectra during electrolysis, however, some other interesting observations were made in these studies. In cases where residual air was present above the melt (during electrode insertion, addition of chemicals, etc.), the reduced titania cathode material was observed to re-oxidize rapidly. Fig. 15 shows a photograph of a portion of the cathode material that was originally reduced (by TIMET using hydrogen gas) after it was inserted in the melt (but not polarized) for a short time. The portion that was submerged in the melt remained reduced (black) while the portion that was exposed to the vapor space reoxidized (white), presumably back to the stoichiometric rutile. 


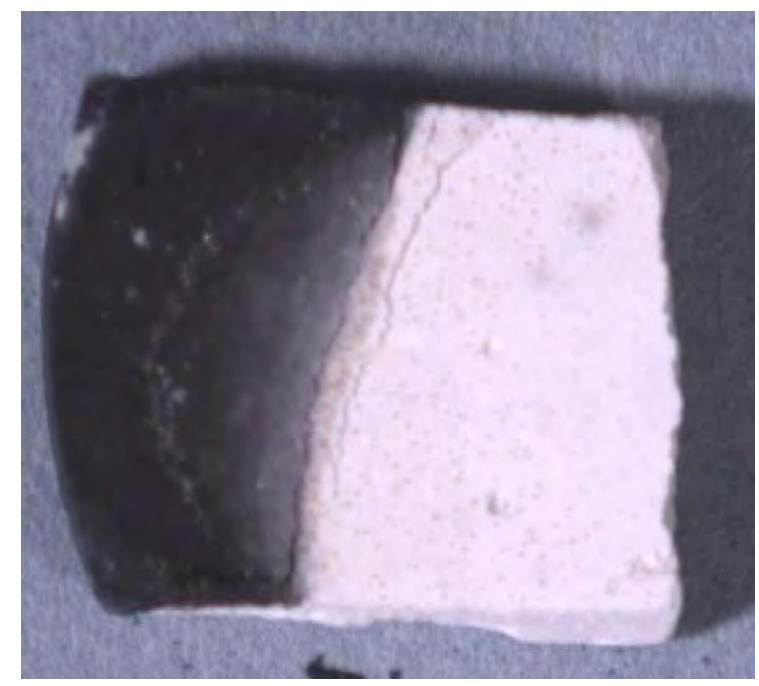

Fig. 15. Portion of "Reduced" Titania Cathode Material that had been Partly Inserted in Molten $\mathrm{CaCl}_{2}$ but Not Polarized

Finally, XRD data were also obtained from a sample of TIMET-reduced titania that had been used as a cathode in one of the experiments. Cathodic current density of a approximately $0.1 \mathrm{~A} \mathrm{~cm}^{-2}$ had been passed through the material for about 10 minutes. The cathode remained black after removal from the melt and appeared to have grayblack metallic nodules on it. The top surface of frozen melt was removed and XRD was obtained of the material. The results are shown in Fig. 16. They indicate the presence of two reduced phases of titantia, $\mathrm{Ti}_{2} \mathrm{O}_{5}$ and $\mathrm{Ti}_{2} \mathrm{O}_{3}$ as well as calcium titanate and metallic calcium. The reduced titania phases are expected: either they are the original reduced components of the electrode or were formed during electrolysis from $\mathrm{TiO}_{2}$. The presence of titanate is also not surprising since it has been observed previously as a reaction product on titania cathodes in calcium chloride melts. However, the relatively large amount of metallic calcium and the absence of metallic titanium suggest several possibilities that are intriguing. One possibility is that $\mathrm{Ca}$ metal only formed in this short test, indicating that $\mathrm{Ca}$ and not Ti may be the first reduction product formed during the electrowinning of Ti metal. If this is the case, then current inefficiencies may be related to the fate of $\mathrm{Ca}$ metal in the melt and studies of this step of the mechanism are warranted in future work. (A similar conclusion could be reached if the Ca metal formed in parallel with the Ti.) A second possibility is that Ti metal was formed but that it reoxidized in air prior to analysis. This would still not preclude an important role for $\mathrm{Ca}$, although the relative amounts of $\mathrm{Ti}$ and $\mathrm{Ca}$ metal would have to be ascertained under more controlled atmospheric conditions. 


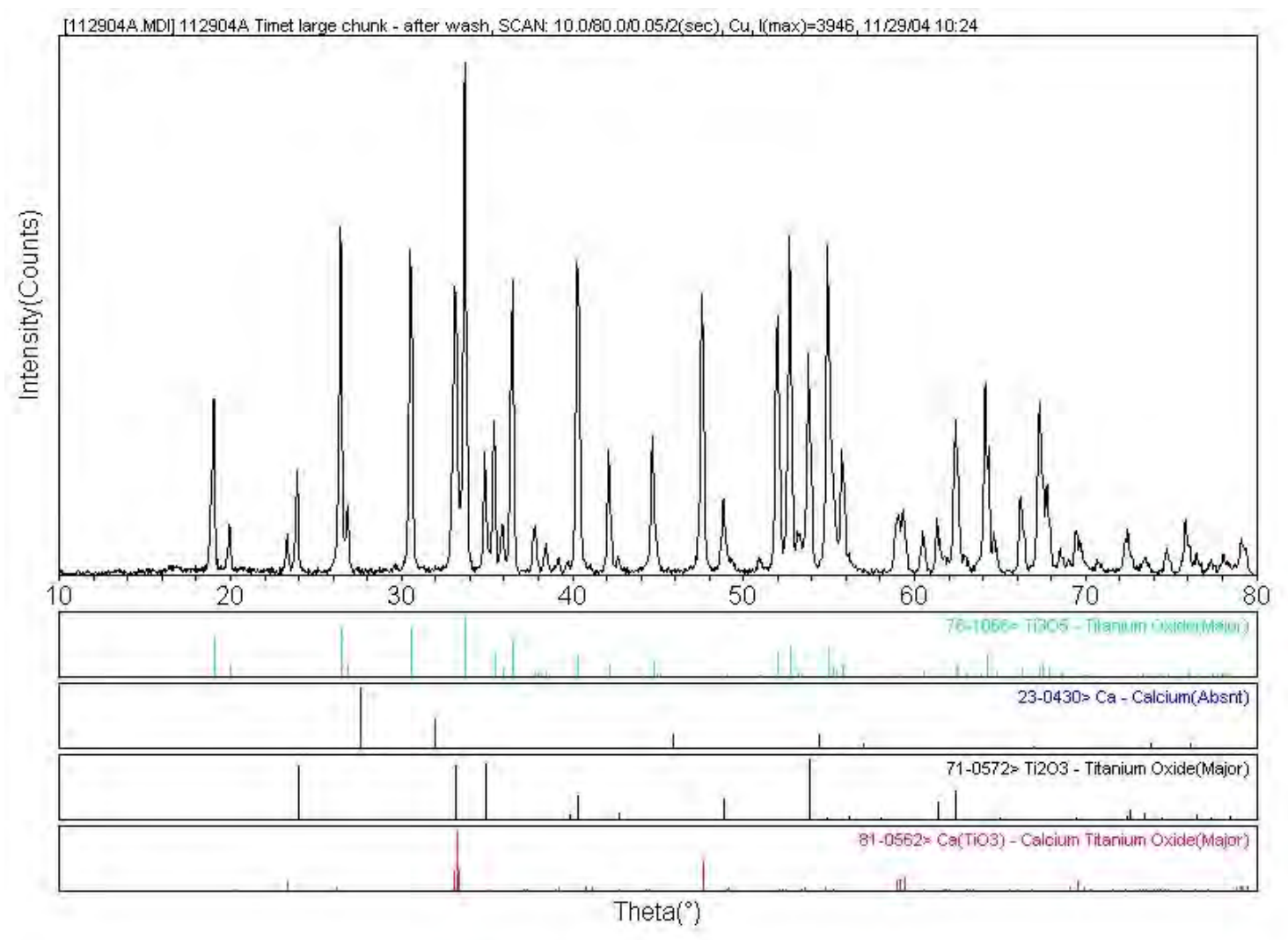

Fig. 16. XRD Pattern from TIMET-Reduced Titania Cathode after Electrolysis in $\mathrm{CaCl}_{2}$ $+1 \% \mathrm{CaO}$ melt at $900^{\circ} \mathrm{C}$.

\subsection{Relationship to Current Efficiency}

Since chemical "tags" for the identification of the species of interest in connection with current efficiency, i.e. calcium chloride complexes, oxide ions, Ca metal and dissolved $\mathrm{CO}_{2}$, could not be obtained in this work, little can be said concerning their relationship to current efficiency in titanium reduction cells. Failure to identify these tags is attributed to a combination of factors including the molecular structure (or lack of it) of the melts and less-than-sufficient sensitivity of the technique to the concentrations of species in the melt under the conditions tested. 


\subsection{Conclusions}

Raman spectroscopy was applied to $\mathrm{CaCl}_{2}$ melts at $900^{\circ} \mathrm{C}$ under both non-electrolyzed and electrolyzed conditions. The later used titania cathodes supplied by TIMET, Inc. and graphite anodes. Use of pulse-gating to collect the Raman spectra successfully eliminated any interference from black-body radiation and other stray light. The spectrum of molten $\mathrm{CaCl}_{2}$ exhibited no distinct, resolvable bands that could be correlated with a calcium chloride complex similar to $\mathrm{MgCl}_{4}{ }^{2-}$ in $\mathrm{MgCl}_{2}$ melts. Rather, the low frequency region of the spectrum was dominated by a broad "tail" arising from collective oscillations of both charge and mass in the molten salt "network." Additions of both $\mathrm{CaO}$ and $\mathrm{Ca}$ at concentrations of a percent or two resulted in no new features in the spectra. Addition of $\mathrm{CO}_{2}$, both chemically and via electrolysis at concentrations dictated by stability and solubility at $900^{\circ} \mathrm{C}$ and 1 bar pressure, also produced no new bands that could be correlated with either dissolved $\mathrm{CO}_{2}$ or the carbonate ion. These results indicated that Raman spectroscopy, at least under the conditions evaluated in the research, was not well suited for following the reactions and coordination chemistry of calcium ions, nor species such as dissolved metallic $\mathrm{Ca}$ and $\mathrm{CO}_{2}$ that are suspected to impact current efficiency in titanium electrolysis cells using molten $\mathrm{CaCl}_{2}$. Raman spectra of TIMET titania electrodes were successfully obtained as a function of temperature up to $900^{\circ} \mathrm{C}$, both in air and in-situ in $\mathrm{CaCl}_{2}$ melts. However, spectra of these electrodes could only be obtained when the material was in the unreduced state. When reduced, either with hydrogen or within an electrolysis cell, the resulting electrodes exhibited no measurable Raman bands under the conditions used in this work. 


\subsection{References}

1. B. Borresen, G. A. Voyiatzis, and G. N. Papatheodorou, "The $\mathrm{Cd}_{2}{ }^{2+}$ in Molten Metal Halides and at Electrode Interfaces," Phys. Chem. Chem. Phys., 1, 3309 (1999).

2. J. H. R. Clarke and R. E. Hester, "Vibrational Spectra of Molten Salts. VI. Raman Spectra of Indium Trichloride-Alkali-Metal Chloride Mixtures," J. Chem. Phys., 50, 3106 (1969).

3. J. Giergiel, K. R. Subbaswamy, and P. C. Eklund, "Light Scattering from Molten Alkali Halides," Phys. Rev. B, 29, 3490 (1984).

4. B. Gilbert, G. Mamantov, and G. M. Begus, "Raman Spectra of Aluminum Fluoride Containing Melts and the Ionic Equilibrium in Molten Cryolite Type Mixtures," 62, 950 (1975).

5. E. W. Mitchell and C. Raptis, "Raman Scattering from Molten Alkali Halides, J. Phys. C: Solid State Phys., 16, 2973 (1983).

6. S. N. Yannopoulos, A. G. Kalampounia, A. Chrissanthopoulos, and G. N. Papatheodorou, "Temperature Induced Changes on the Structure and the Dynamics of the "Tetrahedral" Glasses and Melts of $\mathrm{ZnCl}_{2}$ and $\mathrm{ZnBr}_{2}$," J. Chem. Phys., 118, 3197 (2003).

7. S.Y. Yoon, J.H. Flint, G.J. Kipouros, and D.R. Sadoway, "Raman Scattering Studies of Molten Salt Electrolysis of Light Metals," Energy Reduction Techniques in Metal Electrochemical Processes, R.G. Bautista and R. Wesely, editors, TMS/AIME, Warrendale PA, 1985, pp. 479-490.

8. D. A. Long, Raman Spectroscopy, McGraw-Hill, New York, 1977.

9. M. Maeda and A. McLean, Transactions of the ISS, September 1986, pp. 61-65. See Figs. 5 and 8. 


\section{Distribution}

No. of

Copies

OFFSITE

L. Christodoulou

Program Manager

DARPA/DSO

3710 North Fairfax Drive

Arlington, VA 22203

M. Earlam (3)

Process Engineer

TIMET

PO Box 2128

Henderson, NV 89009

S. Fox

Director Corporate Research

TIMET

8000 West Lake Mead Drive

Henderson, NV 89015
No. of

Copies

ONSITE

11 Pacific Northwest National Laboratory

S. Baskaran

K2-44

G. L. Graff

K3-59

C. A. Lavender

$\mathrm{K} 2-44$

L. M. Peurrung

$\mathrm{K} 2-50$

M. T. Smith

$\mathrm{K} 2-03$

C. F. Windisch Jr. (6)

K2-44

Distr. 1 